\title{
TRABALHAR COM FILOSOFIA NA EDUCAÇÃO: NECESSIDADE E POSSIBILIDADE*
}

Marcos Antônio Lorieri**

\section{RESUMO}

O artigo é uma reflexão sobre a filosofia como componente necessário na educação básica: ensinos fundamental e médio. Argumenta favoravelmente a respeito da necessidade e da possibilidade do trabalho com a filosofia na formação de crianças e jovens e oferece algumas indicações.

Palavras-chave: filosofia; educação; ensino; formação.

\section{INTRODUÇÃO}

Pode-se pensar em ao menos três relações entre filosofia e educação: $1^{\text {a) }}$ ) filosofia como processo de reflexão que pensa a educação e que busca sentidos ou significados para a própria ação educativa; $2^{a}$ ) filosofia como conteúdo necessário na formação dos educadores; $3^{\mathrm{a}}$ ) filosofia como componente necessário na formação de crianças e jovens.

A filosofia é entendida, aqui, como um grande esforço dos seres humanos para saberem de si e da realidade de que fazem parte, buscando especialmente compreender o significado profundo dessa realidade e da própria existência humana. Neste sentido, ela é entendida como busca ou amor da sabedoria. Filo-sofia: amor, bem querença (filo) da sabedoria (sofia).

Sabedoria é mais que só conhecimento: é ter conhecimentos e saber articulá-los de tal modo que, dessa articulação reflexiva, crítica,

\footnotetext{
* Artigo recebido em 4/3/2007 e aprovado em 22/5/2007.

** Programa de Pós-graduação em Educação da Uninove. Centro Universitário Nove de Julho, São Paulo. E-mail: lorieri@isti.com.br
} 
profunda, abrangente, surjam sentidos ou referências significativas de tal modo abrangentes (sempre se fazendo e refazendo-se no movimento constante da história conflituosa da humanidade), nas quais as particularidades, inclusive as de cada vida humana, ganhem significação. As significações têm um grande peso na articulação do modo de produção da vida humana, que é sempre social. Fazer filosofia é fazer algo profundamente político porque é buscar produzir sabedoria que "orienta" ou intenciona as práticas humanas: sabedoria que surge nelas, de dentro delas e para elas. Às ações, assim produzidas, chamamos de práxis: práticas humanas carregadas de intenções, isto é, carregadas de significações.

Podemos dizer que a filosofia é o esforço continuado da humanidade para produzir as intencionalidades ou as significações da própria existência humana e, por conseguinte, da própria realidade onde a existência humana se dá e das práticas que os seres humanos realizam nessa mesma realidade. Nesse esforço, inclui-se o esforço de análise crítica de toda produção de significações, ou seja, de análise crítica da própria produção filosófica.

A Educação é uma das práticas humanas, e das mais importantes: é a prática humana que se propõe a ajudar os seres humanos a se tornarem melhores pessoas. Isso inclui procurar ajudar as pessoas a estabelecerem as melhores relações possíveis com a natureza, com os demais seres humanos e consigo próprias, na construção de um modo de ser no mundo que faça bem a todos, assim como ao próprio mundo.

Este artigo faz reflexões sobre a filosofia como componente necessário na formação de crianças e jovens, buscando enfocar a terceira das três relações mencionadas no primeiro parágrafo. Ao fazê-lo, apresenta idéias e argumenta a respeito da necessidade da filosofia na formação de crianças e jovens e a respeito da possibilidade do que denominamos de ensino de filosofia.

\section{NeCESSIDADE DA FILOSOFIA NA EDUCAÇ̃̃o DE CRIANÇAS E JOVENS}

Se há necessidade de algo, por força dessa necessidade, devem ser encontrados caminhos que o possibilitem. A filosofia é uma necessidade para todas as pessoas porque é através dela que as pessoas podem produzir de maneira reflexiva, crítica, metódica, profunda e abrangente algum significado, algum sentido, para sua existência, o que engloba produzir algum significado ou sentido para a realidade de que 
fazem parte. E isso inclui produzir significado ou sentido para suas ações, para o próprio esforço de busca de conhecimentos, para o próprio esforço de dizer que algo é belo ou não, para o próprio esforço de dizer da vidacom-os-outros e da necessidade, ou não, da regulação de uma tal vida em comum.

As religiões são formas de conhecimento que oferecem sentidos ou significados, mas não são produções que se oferecem a um exame reflexivo e crítico: elas são doutrinas que pedem adesão pela fé, e não pela compreensão do que chamamos de racional. Ainda que a atitude de fé não seja necessariamente uma atitude irracional, há argumentos racionais que podem, de alguma forma, justificar o ter fé.

$\mathrm{Na}$ atual situação histórica da humanidade, marcada pela maneira ocidental de pensar a existência humana, de pensar a realidade em geral e as produções humanas nela (a vida social, a organização do poder, as morais, os conhecimentos, as manifestações artísticas, a linguagem, a própria História), os sentidos ou significados hegemônicos têm sido "dados" pela produção filosófica. Quando uma produção filosófica tornase hegemônica como "doadora de sentidos", constitui uma ideologia. Exemplo marcante é a ideologia liberal: se observarmos bem, é dentro dela e "de dentro dela" que são veiculados os significados ou os sentidos para tudo o que se refere à existência humana e à realidade na qual ela acontece. É uma "referência ampla". Assim foi, também, a visão teológico-filosófica da escolástica medieval. São exemplos de totalidades referenciais significativas.

Ora, se é verdade que as grandes referências de uma época como a nossa são "dadas" por uma filosofia que se tornou ideologia, nada mais urgente e necessário, para todas as pessoas, que uma compreensão dessa mesma ideologia e a capacidade de examiná-la reflexivamente, criticamente, metodicamente, profundamente: ou seja, à maneira filosófica.

$\mathrm{Ou}$ as pessoas fazem uma tal análise e decidem se querem, ou não, tal "filosofia", ou outra (seria possível não querer nenhuma?), ou elas a receberão "dada" por uma imposição nada clara: a imposição possibilitada pela força da persuasão publicitário-ideológica e possibilitada, mais ainda, pela falta de condições de análise filosófica à qual as pessoas são condenadas. Não é permitido que as pessoas possam aprender a filosofar. Não é permitido que as pessoas possam, desde o mais cedo possível, se achegar às diversas produções filosóficas para, de dentro 
delas, aprenderem a filosofar. Não é permitido que as pessoas, desde o mais cedo possível, possam aprender a analisar "respostas" filosóficas às questões de fundo, sempre postas pela humanidade. Não é permitido que as pessoas tomem e retomem essas questões de fundo, sem as escamotear, e aprendam a colocá-las e recolocá-las de forma cada vez mais atenta e clara. Não é permitido que as pessoas, ao serem convidadas a colocar e recolocar as questões de fundo, possam fazê-lo cotejando, a sua maneira de as colocar, com a maneira como os considerados grandes filósofos o fizeram. Muitas vezes não é permitido às pessoas, mesmo tendo acesso aos grandes filósofos, colocá-los em questão.

Tudo isso precisa ser permitido. Tudo isso precisa acontecer porque é uma necessidade, para todas as pessoas, participar da construção das referências que indicam sentidos ou direções para suas vidas. A nossa vida compete a cada um de nós vivê-la. É verdade que não conseguimos vivê-la sem a compartilharmos, de algum modo, com outras pessoas. Mas devemos poder ter o direito de combinar a forma de o fazer e os significados que queremos que a orientem. Se não, não somos sujeitos. Somos objetos. E como ser tidos como objetos é uma maneira de nos desnaturar, temos de ter o direito de reagir a isso. É parte intrínseca de uma tal reação o decidir pelas significações ou pelos sentidos. Quando afirmamos que temos um tal direito, afirmamos uma necessidade. Temos, pois, de filosofar: o filosofar é uma necessidade.

Se uma necessidade, não é algo inútil. A fala da inutilidade da filosofia é conveniente a certos interesses particularistas; os donos desses interesses pretendem que poucas pessoas (de preferência eles próprios) "filosofem" e que apenas eles divulguem os resultados de suas reflexões "interessadas" que devem, por sua vez, ser inculcadas na grande massa em que se juntam as pessoas. Daí a reserva de domínio do filosofar para os poucos que sempre supõem a "incompetência" de todos os outros para o filosofar.

Com certeza, a filosofia não é inútil: ela é útil. Vale lembrar o que diz Chauí a respeito da utilidade da filosofia.

Qual seria, então, a utilidade da Filosofia? Se abandonar a ingenuidade e os preconceitos do senso comum, for útil; se não se deixar guiar pela submissão às idéias dominantes e aos poderes estabelecidos, for útil; se conhecer o sentido das criações humanas nas artes, nas ciências e na política, for útil; se dar a cada um de nós e à nossa sociedade os meios para serem conscientes de si e de suas ações 
numa prática que deseja a liberdade e a felicidade para todos, for útil, então podemos dizer que a Filosofia é o mais útil de todos os saberes de que os seres humanos são capazes. (CHAuí, 1994, p. 18)

Estas idéias constam em outros textos e devem ser reiteradas, especialmente para os educadores responsáveis pelo trabalho nas salas de aula e, em especial, para os gestores das escolas e dos sistemas educacionais. É necessário que as pessoas pensem a respeito daquilo que tem sido denominado, aqui, de "questões de fundo" que constituem as temáticas básicas relativas aos sentidos ou significados da existência humana e da realidade na qual esta existência ocorre. As temáticas relativas ao "ser gente"; à sociedade e a possíveis melhores formas de seu ordenamento; ao poder; à liberdade; à justiça; ao que deve ser considerado como bom, especialmente no tocante às atitudes das pessoas, têm relação direta com as "referências", princípios, ideais, critérios de que nos servimos para orientar a forma como organizamos a vida em comum na "cidade". Nas escolas, estas referências são, de algum modo, "passadas". Por que não trabalhá-las de forma dialógica, reflexiva, crítica e criativa, num processo de iniciação filosófica?

Precisamos falar em "iniciação filosófica". Trata-se de um entendimento, de certa forma, novo. Trata-se de entender o que significa educar filosoficamente as pessoas desde o mais cedo de suas vidas. Isso significa buscar prepará-las para participarem com competência de algumas definições fundamentais que se renovam ao longo da história humana. Essas definições são orientadoras, juntamente com outros fatores, da forma de ser das sociedades e das pessoas nelas.

Definir o que é ser pessoa, que todos os seres humanos devem ser considerados como pessoas, e o que é uma "vida boa" para todas as pessoas é essencial para se ter parâmetros comuns na organização da "cidade", isto é, da sociedade. É, também, essencial definir o que seja justo (e justiça), o que é certo e errado, o que é direito e dever. E é, também, essencial buscar consensos sobre o que é verdade, sobre a importância, ou não, de se ter conhecimentos e quais conhecimentos; sobre o que podemos entender por conhecimento e o que entendemos sobre o que é pensar e "pensar bem".

Talvez seja necessário buscar referências que nos ajudem a entender melhor o que é este mundo material imenso e, nele, o nosso planeta Terra e, na Terra, o que é a natureza e como devemos viver numa 
relação "adequada" com ela. E o que é uma "relação adequada" com a natureza. (LORIERI, 2002, p. 43-45)

A quem compete produzir essas definições e referências? Não cabe pensar em apenas alguns as produzindo. Cabe pensar que todos devam participar de amplas discussões para a sua produção e para a sua re-construção contínua e continuada à medida que as situações históricas o vão exigindo.

Como, porém, as pessoas, todas as pessoas, poderão participar de tais discussões de forma serena, mas firme e colaborativamente, se não tiveram oportunidades de se preparar para isso, envolvendo-se, desde cedo, em tal exercício?

As crianças e os jovens buscam pelas significações para, nelas, situar suas experiências singulares de vida humana. Encontram-nas aprontadas no seu cultural e são, dentro de um tipo de educação "domesticadora" (Paulo Freire), levadas a aceitá-las "docilmente", submissamente. Tais "significações aprontadas" servem sempre a interesses consolidados ou a formas de viver que podem não mais atender às novas necessidades que irrompem sempre no dinamismo histórico da própria humanidade. A construção renovadora da humanidade exige, sempre, a reconstrução de suas próprias significações e, tal reconstrução, é uma tarefa de todos e não, apenas, de alguns "iluminados" que tentam sempre impô-las a serviço de interesses particularistas.

Para que todos possam participar efetivamente dessa reconstrução necessária das significações, é fundamental que todos sejam educados, para tal, desde cedo. É necessária uma educação para o filosofar que mantenha nas crianças e nos jovens o interesse legítimo pelas "questões de fundo" (as que indicam a busca das significações ou dos "fundamentos") e os "instrua" na melhor forma de colocá-las e de buscar insistentemente respostas para elas. Crianças e jovens precisam e, por isso, têm o direito de aprender a ser rigorosos, radicais e abrangentes na análise das questões de fundo e na análise das "respostas aprontadas" com que se defrontam no seu cultural.

Lipman defende que o valor educativo da filosofia seja posto à disposição das crianças e dos jovens o mais cedo possível. E defende-o por todas as razões educativas a favor da filosofia expressas anteriormente. Ele indica a necessidade de crianças e jovens serem inseridos no conhecimento dos ideais reguladores da vida humana que toda cultura 
tem, mas, principalmente, de o serem de uma maneira reflexiva e crítica a ponto de poderem desenvolver um pensamento autônomo. "A filosofia oferece um fórum no qual as crianças podem descobrir, por si mesmas, a relevância, para suas vidas, dos ideais que norteiam a vida de todas as pessoas" (LipMan, 1990, p. 13). Não só descobrir, mas analisar esses ideais e colocá-los sob a mira de exames rigorosos. Só assim serão ajudadas a não serem passivas diante de tais ideais e sim ativas na sua contínua articulação.

Para muitos adultos a experiência de se admirar e refletir nunca exerceu nenhuma influência sobre suas vidas. Assim, estes adultos deixaram de questionar e de buscar os significados de sua experiência e, finalmente, se tornaram exemplos de aceitação passiva que as crianças acatam como modelos para sua própria conduta. Desse modo a proibição de se admirar e questionar se transmite de geração para geração.

Em pouco tempo, as crianças que agora estão na escola serão pais. Se pudermos, de algum modo, preservar o seu senso natural de deslumbramento, sua prontidão em buscar o significado e sua vontade de compreender o porquê de as coisas serem como são, haverá uma esperança de que ao menos essa geração não sirva a seus próprios filhos como modelo de aceitação passiva. (LipMAN et al., 1994, p. 55)

Somando argumentos a favor da necessidade da filosofia na educação de crianças e jovens, outros pensadores têm se manifestado, especialmente nos últimos tempos. Severino (2002, p. 185), ao tratar da necessidade da filosofia na educação, fala em desenvolvimento da "sensibilidade para a compreensão da existência" como aspecto necessário da formação humana. Uma tal formação implica em desenvolver a subjetividade com as suas variadas formas de sensibilidade: sensibilidade ou percepção de conceitos; sensibilidade relativa aos valores morais e estéticos, aos valores políticos etc. "É toda esta esfera do exercício da dimensão subjetiva da pessoa que nos torna efetivamente humanos", diz ele (p. 185), entendendo a dimensão subjetiva como a

capacidade que temos de poder identificar, de atribuir sentidos ou significações às coisas e situações e de poder agir de acordo com esses sentidos e não mecanicamente por força dos instintos ou de outros fatores físicos, químicos, biológicos, psíquicos, ou melhor, a capacidade de sobrepor a esses fatores naturais um elemento 
diferenciado, um motivo significador, que dá sentido a nossos atos. (SEVERINO, 2002, p. 186)

Ora, se toda forma de educação visa à formação humana, se a formação humana implica a capacidade de atribuir ou produzir significações e se a filosofia é a forma de conhecimento específica para tal produção, é forçoso concluir pela sua necessidade no processo educacional. "É por tudo isso que não pode haver educação, verdadeiramente formativa, sem a participação, sem o exercício e o cultivo da filosofia, em todos os momentos de formação de pessoas, do ensino fundamental ao superior" (SEVERINo, 2002, p. 187).

Morin propõe que se recupere a importância da filosofia que faz parte da cultura humanista. "A cultura humanista é uma cultura geral que, por meio da filosofia, do ensaio e da literatura coloca problemas humanos fundamentais e incita à reflexão" (MoRIN, 2002a, p. 17).

A cultura humanista que envolve a literatura, as ciências humanas e, de modo especial, a filosofia coloca "problemas humanos fundamentais" como os já mencionados anteriormente: o problema da realidade, o da existência humana e do seu significado, o do conhecimento, o dos valores em geral e o dos valores morais em especial, o problema do que é viver em sociedade e o do poder dentro dela. Além disso, para o enfrentamento destes problemas, a filosofia precisa incitar à reflexão e fazer bom uso dela, de maneira crítica e profunda. O "conveniente desta cultura" é o "interrogar-se sobre o homem, a sociedade, o destino, a vida, a morte, o outro lado" (Morin, 2000, p. 29). E "é uma cultura que permite reflexão, meditação. É uma cultura que permanece num nível de problemas em que o conhecimento está ligado à vida de cada um e à sua vontade de se situar no universo" (Idem, p. 30).

Ele aponta dois importantes papéis educativos do filosofar: provocar e manter vivo o interesse pelos problemas humanos fundamentais e provocar para a reflexão, para a crítica, para o exame rigoroso das idéias e para a problematização. Não só provocar, mas ajudar a desenvolver uma tal forma de pensamento: "A filosofia deve contribuir eminentemente para o desenvolvimento do espírito problematizador. A filosofia é, acima de tudo, uma força de interrogação e de reflexão, dirigida para os grandes problemas do conhecimento e da condição humana" (MoRIN, 2002, p. 23).

Gallo e Kohan, apontam na mesma direção ao indicarem o "para quê" da filosofia. Este "para quê" "envolve a dimensão do sentido". 
"[...] A filosofia contribui para se manter aberta e sempre presente a pergunta pelo sentido de como vivemos e do que fazemos (LARrosa, 1994, p. 80). Essa é sua função social principal" (GALlo e KoHAN, 2000, p. 188-189). Além disso, ela contribui para que os jovens desenvolvam um pensamento autônomo que é condição necessária para que se tornem pessoas capazes de escolhas. Daí a necessidade do que denominam "experiências de pensamento" pelas quais todo educando deve passar.

é importante que todo jovem, ao ter contato com a filosofia, possa desenvolver experiências de pensamento, aprendendo a reconhecer e a produzir, em seu nível, conceitos, a fazer a experiência da crítica e da radicalidade sobre a sua própria vida, a desenvolver uma atitude dialógica frente ao outro e ao mundo e, fundamentalmente, possa aprender uma atitude interrogativa frente ao mundo e a si mesmo.

Pensamos que uma educação para a autonomia, no sentido da formação de indivíduos que possam escolher por si mesmos em que mundo querem viver, só pode ser tal se nela tiver lugar a filosofia. (Gallo e Kohan, 2000, p. 195)

Não é possível separar filosofia e educação. E, se educação é necessidade óbvia, óbvia se torna a necessidade da filosofia que dela não pode se desprender, pois ambas se perguntam pelo ser humano a ser "formado", e isto depende de uma interpretação do homem, da sociedade, do seu tempo. Sem uma tal interpretação não há educação: sem filosofia não há sentido, direção, para a educação. E nem para a vida. Ainda que tal direção não esteja clara para quem educa e para quem vive, há sempre alguma! É necessário saber qual. É necessário avaliá-la. É necessário definir-se por uma. É preferível, e mais digno, construí-la ou participar de sua construção. Mas, para participar, é preciso saber fazer: daí a necessidade de todos sabermos fazer filosofia. Todos, e não apenas alguns.

Desse modo, sendo a filosofia imprescindível subsídio de formação, ela pode e deve estar presente desde o momento em que a pessoa tenha condições para começar a pensar. Parece, então, totalmente acertada a proposta de ensino de filosofia para crianças, desde os tempos da escola fundamental, pois toda criança é sensível à justificação, ou seja, não só é capaz de pensar, mas também de compreender o pensamento. [...] pois, o que se tem em mente é justamente ajudar a criança a se apropriar de conceitos e valores, a 
praticar seu pensamento, no sentido mesmo de exercer sua subjetividade lógica, ética e estética. E isso é essencialmente formativo. [...] No que concerne à formação dos adolescentes no ensino médio, a formação filosófica é ainda mais imprescindível e, por isso, é preciso lutar contra os fatos e providenciar para que sejam criadas as condições para que seu ensino venha a ocorrer de forma sistemática. (SEVERINO, 2002, p. 189)

E isto por quê? Por tudo o que foi dito anteriormente. Vivemos numa época em que se dá muito prestígio à informação. Mas temos de saber utilizá-la: saber articular as informações; saber avaliar a sua veracidade; saber a sua pertinência para os problemas que nos são postos pela vida.

Somos informados pelas ciências da natureza, pelos técnicos, pelos jornais, por alguns programas de televisão... mas não há informação "filosófica". [...] a filosofia é incompatível com as notícias e a informação é feita de notícias. Muito bem, mas é só informação que buscamos para entendermos melhor a nós mesmos e o que nos rodeia? (SAVATER, 2001, p. 5)

Com certeza não: precisamos das informações, mas precisamos saber articulá-las para construir entendimentos, explicações e significados. Para tanto há necessidade do trabalho do pensamento. Um trabalho que demanda certas qualidades: a reflexão, a criticidade que inclui a problematização, o rigor, a profundidade, a contextualização. A filosofia ajuda nesta direção e é o grande espaço de construção, de preferência coletivo, dos significados fundamentais para nossas vidas.

Possibilidade DO ENSINO DE FILOSOFIA E INDICAÇÕES PARA SUA VIABILIDADE

Se necessário, deve ser possível de algum modo. Este "algum modo" não pode ser, evidentemente, de "qualquer modo". Terá que ser de um modo adequado à tarefa que é proposta. É possível um tal trabalho com crianças e jovens? A resposta é sim. É possível tanto ensinar certas coisas em filosofia como é possível desenvolver um trabalho que possibilite o aprendizado do filosofar. Há conteúdos a serem ensinados, especialmente certos conceitos e certos procedimentos, os quais precisam 
ser aprendidos; bem como é possível aprender (portanto ensinar) quais são as questões fundamentais sempre colocadas pelo esforço filosófico da humanidade ao longo da história e algumas das respostas dadas a elas. E é possível conhecer filósofos que foram decisivos na produção do pensamento filosófico. Estes aprendizados são necessários para o trabalho com os conteúdos, isto é, para um trabalho de reflexão rigorosa, radical e abrangente sobre as temáticas e com base em questões pertinentes a elas. Não se trata, apenas, de saber quais são as temáticas, quais são as questões, quais são algumas das respostas dadas a elas e, eventualmente, alguns autores. E não basta, também, saber as exigências metodológicas do filosofar. Tudo isso é necessário, mas o mais importante é o trabalho com essas temáticas, com essas questões, com essas "algumas respostas" (especialmente as que estão hegemonicamente presentes em nosso meio cultural) e com o método da investigação filosófica. É este trabalho que vai gerando pessoas com formação filosófica. Este trabalho é possível. É nele, tanto no ensino fundamental como no ensino médio que se pode promover o desenvolvimento do pensamento reflexivo, crítico, rigoroso, profundo, abrangente e criativo, bem como o desenvolvimento do gosto pelas temáticas essencialmente filosóficas. É possível desenvolver este gosto e, mais que isso, a percepção de que não se devem escamotear essas temáticas e as questões que elas suscitam. Tal escamoteamento se dá pelo fato de não se prestar atenção suficiente a elas e pelo fato de serem oferecidas respostas prontas, sem o "convite pedagógico" e político para pensar as razões dessas respostas.

antes de propor aos estudantes uma filosofia acabada, convidá-los a examinar lucidamente e à luz de sua própria experiência, as questões que eles correm o risco de escamotear. [...] Ensinar os estudantes a filosofar é convidá-los a pensar por eles mesmos, sugerindo-lhes não esquecer, no momento de fazê-lo, certos dados que os filósofos, os cientistas, os artistas procuraram esclarecer e que dão à questão toda a sua complexidade como toda a sua dimensão. Ensinar a filosofar não é, então, apenas ajudar a tomar consciência das questões fundamentais em toda a sua amplitude, mas é, também, sugerir elementos de solução; é elucidar noções ambíguas; é lembrar de modo pertinente a "démarche" de determinado filósofo no momento em que ele encontra uma questão claramente colocada por todos; mas é sempre ajudar o estudante a ver mais claro em sua própria situação. (LAGUEUX, 1980, p. 22) 
Esta é uma proposta possível que tem como elementos básicos algumas idéias e algumas formas de fazer. Por exemplo: é fundamental trabalhar com contextos bem planejados nos quais as temáticas se insiram. Contextos são conjuntos de elementos relacionados entre si constituindo uma significação. O todo, neste caso, só tem esta significação por causa dos elementos que o compõem, pelas relações entre eles e pelas relações deles com o próprio todo. Assim também cada elemento só tem aquela significação naquele todo com aquelas relações. Em cada contexto, cada elemento tem significação específica em virtude do próprio contexto: nada tem significado isoladamente. Os contextos são como que o "berço" das significações dos diversos elementos: em cada contexto diferente, os elementos ganham significações diferentes. Assim é com as palavras: é preciso ser capaz de analisar os contextos nos quais são empregadas, para se poder atinar com seus significados. Há sempre duas exigências básicas aqui: analisar e compreender os contextos e atinar com os significados de cada elemento dentro dele. Há uma terceira: compreender as relações de contextos menores com contextos maiores. Neste caso, os contextos menos amplos são elementos de contextos mais gerais. Há sempre totalidades menores que se inserem em totalidades maiores, o que indica que compreendemos por aproximações sucessivas. O que parece não ser possível é a compreensão de elementos isolados de qualquer totalidade contextual e nem a compreensão, de uma só vez, de cada contexto.

Obviamente que, para séries do ensino fundamental, não cabe tomar totalidades muito amplas como contextos iniciais de análises: há que saber tomar contextos menos amplos e, neles, auxiliar os alunos a identificar as significações. Tanto as significações dos diversos elementos dentro do contexto tomado quanto a significação do próprio contexto como uma totalidade. Isso não se dá por um trabalho mecânico e fragmentado de análises particularistas dos diversos elementos. Isso só é possível num trabalho contínuo de idas e vindas do todo para as partes e das partes para o todo, no qual, dialeticamente, o todo ilumina a significação das partes e as partes e suas relações iluminam a significação do todo. Aos poucos, progressivamente, a compreensão vai sendo obtida: por aproximações sucessivas. O que envolve, obviamente, a compreensão de contextos cada vez mais amplos. Daí a necessidade de saber escolher os contextos para o trabalho filosófico aqui proposto. É neste sentido que se fala de contextos bem planejados. Isto significa que não devem 
ser tomados a esmo, e sim com intenções claras ligadas a objetivos presentes no projeto pedagógico. Significa também que são contextos nos quais os alunos devem poder encontrar motivações para boas questões que os envolvam no diálogo investigativo a respeito de certos temas e na busca de novas informações a respeito. Significa, ainda, que foram pensados como caminho inicial para se chegar a certos conceitos e entendimentos relativos aos temas e para propiciar, com o tempo, condições de leitura de contextos mais complexos e de textos mais elaborados e mais profundos sobre os conteúdos com os quais se vai trabalhando.

Outra idéia importante: não há trabalho filosófico sem conteúdos específicos da filosofia e sem uma metodologia que seja filosófica. As temáticas filosóficas garantem, junto com a metodologia, a especificidade da abordagem filosófica. Os conteúdos da filosofia são certas temáticas, que se apresentam na forma de certas perguntas e certos problemas, para os quais há diversas respostas, algumas das quais presentes com mais força no cultural de cada época histórica e que precisam ser sempre examinadas, avaliadas e, eventualmente re-elaboradas ou mesmo substituídas. Não só: faz parte dos conteúdos da filosofia uma maneira própria de trabalhar as temáticas, as perguntas e as respostas. Esta maneira própria, ou seja, o método, torna-se conteúdo na medida em que ele é constantemente examinado, estudado, avaliado e reconstruído. As temáticas incluem temas e conceitos básicos, problematização e posicionamentos historicamente produzidos. Em aulas de filosofia, esses temas precisam estar presentes; os conceitos básicos a eles relacionados precisam ser utilizados com compreensão cada vez mais clara; problemas e perguntas antigas e novas relativas a esses temas devem ser provocação para a investigação filosófica; e as "respostas" dadas a essas questões, pelos chamados grandes filósofos, devem ser visitadas e revisitadas como caminhos que indicam, também, por onde andar e como andar no caminhar filosófico.

É possível adequar um tal trabalho para alunos tanto do ensino fundamental quanto do ensino médio. No ensino fundamental podem-se privilegiar contextos significativos mais próximos da realidade dos alunos e tomá-los como suscitadores de problemas que caminhem na direção das temáticas filosóficas. As crianças e os jovens colocam-se tais problemas e interessam-se por debatê-los. Acolhê-los em aulas de iniciação filosófica significa não permitir que sejam escamoteados. Significa 
mantê-los sob a mira da "admiração" ou do espanto - e propor que sejam olhados de maneira a se aprender a examiná-los reflexiva e criticamente. Trata-se de um necessário aprendizado inicial. Aprendizado tanto da importância de certos problemas quanto da importância de seu exame na forma indicada. E é possível, também, já iniciar esses alunos, especialmente nas séries finais do ensino fundamental, na tomada de consciência das respostas presentes no seu cultural e no exame reflexivo e crítico delas. Até mesmo em certos textos de filósofos.

Uma terceira idéia cabe aqui nestas indicações. $\mathrm{O}$ exame das temáticas filosóficas a partir dos problemas suscitados nos diversos contextos da existência humana deve ser feito investigativamente. Só assim o filosofar é produzido e, portanto, aprendido. Investigar é procurar saber, é buscar respostas, é estar em caminho na direção de um saber que não se sabe ainda, mas que se pretende saber. Kant diz, em texto que ficou famoso, que o jovem é incapaz de aprender filosofia, pois o que ele deve é aprender a filosofar: "O método peculiar de ensino na Filosofia é zetético, como lhe chamavam os Antigos (de Zetéin), isto é, investigante, e só se torna dogmático, isto é decidido, no caso de uma razão mais exercitada em diferentes questões" (KANT, 1992, p. 175).

Kant não recusava o trabalho de ensino de conteúdos. Mas não queria que os alunos simplesmente os repetissem sem tê-los compreendido. No início do texto citado, afirma que, se não se trabalhar para que o aluno investigue, ao invés de só lhe oferecer conteúdos prontos e acabados, este aluno irá se tornar

portador de uma ciência de empréstimo, que nele estará, por assim dizer, apenas grudada e não desenvolvida, ao passo que suas aptidões mentais permanecerão tão estéreis como dantes, tendo-se tornado, porém, com o delírio da sabedoria, muito mais corrompidas. (KANT, idem, p. 173-174)

Ou, no máximo, ele será "discípulo" de alguma doutrina, até mesmo sem a compreender bem. Ou seja, é necessário que, em aulas de filosofia para crianças e jovens, faça-se um trabalho especial com os temas, as questões, os problemas, os conceitos e as respostas já dadas: este trabalho, mais do que um ensino, deve ser uma investigação motivada por problemas pertinentemente filosóficos (o que se aprende a fazer), relativos a temas filosóficos e levando-se em conta respostas eventualmente já dadas a essas questões pela tradição do pensamento filosófico. 
O estudante que aprende apenas os resultados da investigação não se torna um investigador, mas apenas um estudante instruído. Esta alusão aponta para um dos propósitos educacionais da Filosofia: todo estudante deve tornar-se (ou continuar a ser) um investigador. Para a realização desta meta não há melhor preparo que o que é dado pela Filosofia. A Filosofia é investigação conceitual, que é a investigação na sua forma mais pura e essencial. (LiPMAN, 1990, p. 58)

As "respostas já dadas" devem, preferencialmente, ser as dos chamados grandes filósofos, principalmente no ensino médio. Textos deles devem ser escolhidos com discernimento no tocante às possibilidades de entendimento dos alunos e, se necessário, para facilitar tal entendimento, devem ser apresentados pelo próprio professor numa tradução didática que não comprometa o significado. Mas as posições dos filósofos não devem ser apresentadas como últimas palavras sobre o assunto. São, com todo peso que têm, uma posição a ser analisada e avaliada. $\mathrm{O}$ conselho de Kant parece pertinente aqui:

Também o autor filosófico em que nos baseamos no ensino, deve ser considerado, não como o modelo do juízo, mas apenas como o ensejo de julgarmos nós próprios sobre ele e até mesmo contra ele; e o método de refletir e concluir por conta própria é aquilo cujo domínio o aprendiz está a rigor buscando, o qual também é o único que lhe pode ser útil, de tal sorte que os discernimentos decididos, que por ventura se tenham obtido, ao mesmo tempo têm que ser considerados como conseqüências contingentes dele, conseqüências estas para cuja plena abundância ele só tem de plantar, em si mesmo, a raiz fecunda. (KANT, 1992, p. 175, itálico no original)

Um tal trabalho de investigação pode, evidentemente, ser realizado individualmente por uma pessoa já iniciada na investigação filosófica. Não é o caso de alunos do ensino fundamental e médio: eles precisam da ajuda inicial dos seus professores; uma tal ajuda demanda tempo.

Um caminho profícuo é o de propor um trabalho dialógicoinvestigativo, isto é, um trabalho de investigação realizado em grupo e com a coordenação do professor. Dialogar investigativamente significa conversar de forma ordenada a respeito de um assunto (tema) com a intenção de ter idéias mais claras e possivelmente mais verdadeiras a respeito dele, tanto para si próprio, como para os outros que participam 
da conversa ou do diálogo. Propõe-se aos alunos que busquem o diálogo e não a polêmica.

Paulo Freire, em Educação como prática da liberdade (1975, p. 61-62), distingue diálogo de polêmica. Na polêmica, discute-se com os outros para convencê-los de nossas idéias; no diálogo, conversa-se organizada e examinativamente tanto sobre o que se pensa quanto sobre o que os outros pensam a respeito de um assunto e sobre as razões de cada um para pensar assim. Este exame deve levar todos a estarem dispostos a modificar ou complementar suas posições, se os argumentos (as razões), assim o indicarem.

É que o diálogo, tal como é focalizado aqui, não deve constituir um debate, em que convicções estabelecidas e opostas são defendidas por seus respectivos partidários, mas uma discussão, em que os interlocutores buscam honestamente e sem preconceitos a melhor solução de um problema controvertido. (Perelman; Tyteca, 1996, p. 41-42)

Lipman propõe que o trabalho reflexivo com temáticas filosóficas seja realizado através do diálogo investigativo naquilo que ele denominou de comunidade de investigação. Cada sala de aula, segundo ele, deve ser transformada em uma pequena comunidade de investigação.

O fazer Filosofia exige conversação, diálogo e comunidade, que não são compatíveis com o que se requer na sala de aula tradicional.

A filosofia impõe que a classe se converta numa comunidade de investigação, onde estudantes e professores possam conversar como pessoas e como membros de uma mesma comunidade; onde possam ler juntos, apossar-se das idéias conjuntamente, construir sobre as idéias dos outros; onde possam pensar independentemente, procurar razões para seus pontos de vista, explorar suas pressuposições; e possam trazer para suas vidas uma nova percepção do que é descobrir, inventar, interpretar e criticar. (LIPMAN, 1990, p. 61)

Lipman é um dos pensadores que, na atualidade, defende e propõe um trabalho com filosofia para crianças e jovens. Ao apresentar suas justificativas para um tal trabalho apresenta a da investigação dialógica nestes termos:

A justificativa mais ampla apóia-se no modo pelo qual paradigmaticamente representa a educação do futuro como uma forma de vida 
que não foi ainda percebida e como um tipo de práxis. A reforma da educação tem de ter a investigação filosófica compartilhada na sala de aula como um modelo heurístico. (LipMAN, 1990, p. 34)

Um modelo heurístico e não erístico: o primeiro significa pesquisa ou investigação; o segundo, "a arte de batalhar com as palavras, isto é, de vencer nas discussões" (ABBAGnano, 1970, p. 322). Lipman chama ao segundo de pseudofilosofia e diz, ao se referir a Platão e à sua crítica aos procedimentos, apenas erísticos, próprios dos sofistas:

Não há dúvida de que Platão, especialmente em sua juventude, foi atraído por muito do que os sofistas disseram sobre educação, mas estabeleceu limites quando suspeitou que a ênfase na gramática, retórica e dialética não era equilibrada com a imersão e apropriação pelo estudante da riqueza humanística da cultura.

Tendo tido um professor como Sócrates e um aluno como Aristóteles, Platão teria realmente sido peculiar se não tivesse se sentido aflito pela mascateagem das panacéias educacionais que baixaram aos bandos em Atenas. (LipMAN, 1990, p. 45)

A imersão na, e a apropriação da riqueza humanística da cultura, não deve ser feita apenas repassando aos estudantes os seus conteúdos prontos, como resultados já atingidos pelos que já investigaram anteriormente: ela deve ser feita investigativamente e reconstrutivamente, como o queria Kant. O paradigma da investigação filosófica é, segundo Lipman, o que oferece o melhor preparo para tal. A filosofia é ela mesma, por excelência, educativa porque, além de trabalhar tesouros culturais próprios, ou seja, os conteúdos, ela realiza estudo da forma como pensamos e produz referências importantes para o pensar bem. Além disso, se realizada uma investigação filosófica compartilhada, dialogicamente, os resultados educacionais são prometedores.

Vive-se no Brasil, hoje, um momento auspicioso e rico em relação ao ensino da filosofia. As idéias aqui expostas querem servir de contribuição para os debates que devem continuar a ser feitos de tal maneira que, a partir deles, seja possível encontrar as melhores orientações para o trabalho do filosofar nas escolas como um caminho necessário e rico de formação de crianças e jovens com qualidade de sujeitos construtores de seus destinos e dos destinos da sociedade da qual participam. 


\begin{abstract}
This article has the objective of proposing a reflection on Philosophy as a necessary component in the basic education: the fundamental and the high school teaching. It argues favorably on the necessity and on the possibility of working with philosophy in the education of children and young people and shows indications to it.
\end{abstract}

Keywords: philosophy; education; teaching; formation.

\title{
REFERÊNCIAS
}

ABBAGnANO, N. Dicionário de filosofia. São Paulo: Mestre Jou, 1970.

CHAUÍ, M. Convite à filosofia. São Paulo: Ática, 1994.

FREIRE, P. Educação como prática da liberdade. Rio de Janeiro: Paz e Terra, 1975.

GALlO, S.; KOHAN, W. O. Filosofia no ensino médio. Petrópolis: Vozes, 2000.

KANT, I. Lógica. Rio de Janeiro: Tempo Brasileiro, 1992.

KOHAN, W. O. et al. Filosofia para crianças em debate. Petrópolis: Vozes, 1999.

LAGUEUX, M. Por que ensinar a filosofia? Reflexão. Campinas, n. 18, p. 1229, set.-dez., 1980.

LIPMAN, M. A filosofia vai à escola. São Paulo: Summus, 1990. . et al. Filosofia na sala de aula. São Paulo: Nova Alexandria, 1994.

LORIERI, M. A. Filosofia: fundamentos e métodos. São Paulo: Cortez, 2202.

MORIN, E. e LE MOIGNE, J.-L. A inteligência da complexidade. Trad. Nurimar Maria Falci. São Paulo: Peirópolis, 2000.

MORIN, E. Educação e complexidade: os sete saberes e outros ensaios. Trad. de Edgar de Assis Carvalho. São Paulo: Cortez, 2002a.

. A cabeça bem feita: repensar a reforma, reformar o pensamento. Trad. de Eloá Jacobina. 7. ed. Rio de Janeiro: Bertrand Brasil, 2002b.

PERELMAN, C. e TYTECA-OLBRECHTS, L. Tratado da argumentação: a nova retórica. São Paulo: Martins Fontes, 1996.

SAVATER, F. As perguntas da vida. Trad. de Monica Stahel. São Paulo: Martins Fontes, 2001. 
SEVERINO, A. J. A filosofia na formação do jovem e a ressignificação de sua experiência existencial. In: KOHAN, W. O. Ensino de filosofia: perspectivas. Belo Horizonte: Autêntica, 2002. p. 183-194. 
